Molecules 2002, 7, 706-711

molecules

ISSN 1420-3049

http://www.mdpi.org

\title{
Diazoamino Coupling of a 4-Sulfobenzenediazonium Salt with Some Cyclic Amines
}

\section{Marytė Kažemėkaitė, Zita Talaikyte் $\dot{\dagger}^{\dagger}$ Gediminas Niaura and Eugenius Butkus**}

Institute of Biochemistry, Mokslininku 12, Vilnius 2600, Lithuania, Fax (+370) 2729186.

†e-mail: zitat@bchi.lt

*Author to whom correspondence should be addressed; e-mail: butkus@bchi.lt

Received: 28 August 2002; in revised form 17 September 2002/ Accepted: 19 September 2002 /

Published 30 September 2002

\begin{abstract}
Preparation of several novel potassium salts of 4-substituted aminoazobenzenesulfonic acids by the simple and convenient reaction of insoluble 4-sulfobenzenediazonium chloride with some (hetero)cyclic amines of various ring sizes is reported. The compounds obtained have shown potential antiinflammatory activity in biological testing.
\end{abstract}

Key words: amines, diazoamino coupling, 4-sulfobenzenediazonium chloride, triazenes

\section{Introduction}

Aromatic aminoazo derivatives or triazenes represent a stable aryl diazonium ion source and are thus a class of nitrogen-containing compounds useful for synthetic transformations [1]. In a wellknown classical synthesis the aromatic diazoamino system is formed in the reaction between a diazonium cation and the nucleophilic nitrogen atom of an amine. Usually the diazonium salt involved is not isolated, and an acidic aqueous solution of this reagent is exposed directly to the amine at low temperature in the presence of an excess of base to neutralize the acid used for diazotation. However, such diazoamino couplings are frequently accompanied by side reactions, e.g. C-couplings, decomposition of the diazonium salt, etc., leading to formation of multiple products and low yields [2]. 
Modifications of this synthetic procedure, for example, synthesis on an ion-exchange resin support, have been proposed in order to overcome these complications [3]. These syntheses are further complicated when the aryl diazonium salt is insoluble in water and consequently the coupling reaction has to be performed in a suspension. For example, the syntheses of the sodium salts of 2-, 3-, and 4(3,3-dimethyltriazeno)benzenesulfonic acid [2] require prior isolation and purification of the corresponding diazonium fluoroborates or fluorophosphates which subsequently are added to a cooled solution of dimethylamine in water under a stream of nitrogen. The products were obtained only after saturation of the reaction mixtures with carbon dioxide. As a result of all this, more convenient methods for the synthesis of novel compounds of this class are highly desirable.

In addition, aromatic triazenes are of considerable interest for their reported biological activities, which include antitumour [4,5], antiinflammatory [6,7] and other important properties. Some aminoazo derivatives are of considerable value due to their selective antimetastatic effects and low toxicity $[4,8]$. In recent years this class of compounds has also received attention in the search for potential HIV-1 inhibitors [9]. The sodium salt of 4-(3,3-dimethyltriazeno)benzenesulfonic acid has been found to possess strong antineoplastic activity [10], equivalent to that of the clinically used antitumour drug Dacarbazine $\left(\mathrm{DTIC}^{\circledR}\right)$. Moreover, it also shows strong antiinflammatory action on experimental oedema [6]. Considering all this, the preparation water-soluble compounds with a cyclic aminoazo system bearing a sulfo group in a benzene ring was deemed to be of practical interest.

\section{Results and Discussion}

Herein we report the preparation of several novel potassium salts of substituted 4-aminoazobenzenesulfonic acids using a simple and convenient method, namely the reaction of insoluble 4-sulfobenzenediazonium chloride with heterocyclic and cyclic amines of various ring sizes, i.e. pyrrolidine, piperidine, hexamethyleneimine, morpholine, $\mathrm{N}$-methylpiperazine and piperazine. This synthetic route is represented in Scheme 1.

4-Sulfobenzenediazonium chloride $\left(\mathrm{DS}-\mathrm{SO}_{3} \mathrm{H}\right)$ was obtained by diazotization of sulfanilic acid with $\mathrm{NaNO}_{2}$ in dilute hydrochloric acid according to a published procedure [11]. The precipitated DS$\mathrm{SO}_{3} \mathrm{H}$ was separated from the diazotation mixture by filtration, washed successively with cold water, acetone, and ether, air dried and stored in a refrigerator. To complete the reaction sequence the DS- $\mathrm{SO}_{3} \mathrm{H}$ was slurried in water and treated with the appropriate amine. The reaction requires three equivalents of amine: as a reaction component, for binding of liberated $\mathrm{HCl}$, and for the formation of the sulfonic acid salt. However, after addition of 3 equivalents of an appropriate amine to a suspension of $\mathrm{DS}-\mathrm{SO}_{3} \mathrm{H}$ in water at room temperature and heating to $50^{\circ} \mathrm{C}$ the reaction mixture turns red, indicating the occurrence of a $\mathrm{C}$-coupling side reaction. This side reaction could be avoided by increasing the ratio of the amine component, thus the highest yields of the target compounds were obtained by coupling the amines with $\mathrm{DS}-\mathrm{SO}_{3} \mathrm{H}$ in a $5: 1$ ratio at $50^{\circ} \mathrm{C}$.

Products were isolated as potassium salts after addition of $\mathrm{KOH}$ in methanol to the reaction mixtures. The precipitated crystals were of high purity and additional crystallization from methanolwater or water afforded analytically pure samples of products 1-6. It should be mentioned that in the 
case of piperazine, despite the use of a high excess of this reagent, both nitrogen atoms participated in the coupling reaction with $\mathrm{DS}-\mathrm{SO}_{3} \mathrm{H}$ and as a result, the bis-substituted product, the dipotassium salt of 1,4-bis(4-sulfophenylazo)piperazine (6), was obtained. We succeeded in obtaining the desired monosubstituted product, i.e. the potassium salt of 4-(piperazin-1-ylazo)benzenesulfonic acid (7), by changing the reaction solvent (from water to methanol) while maintaining the same reagent ratio.

\section{Scheme 1}

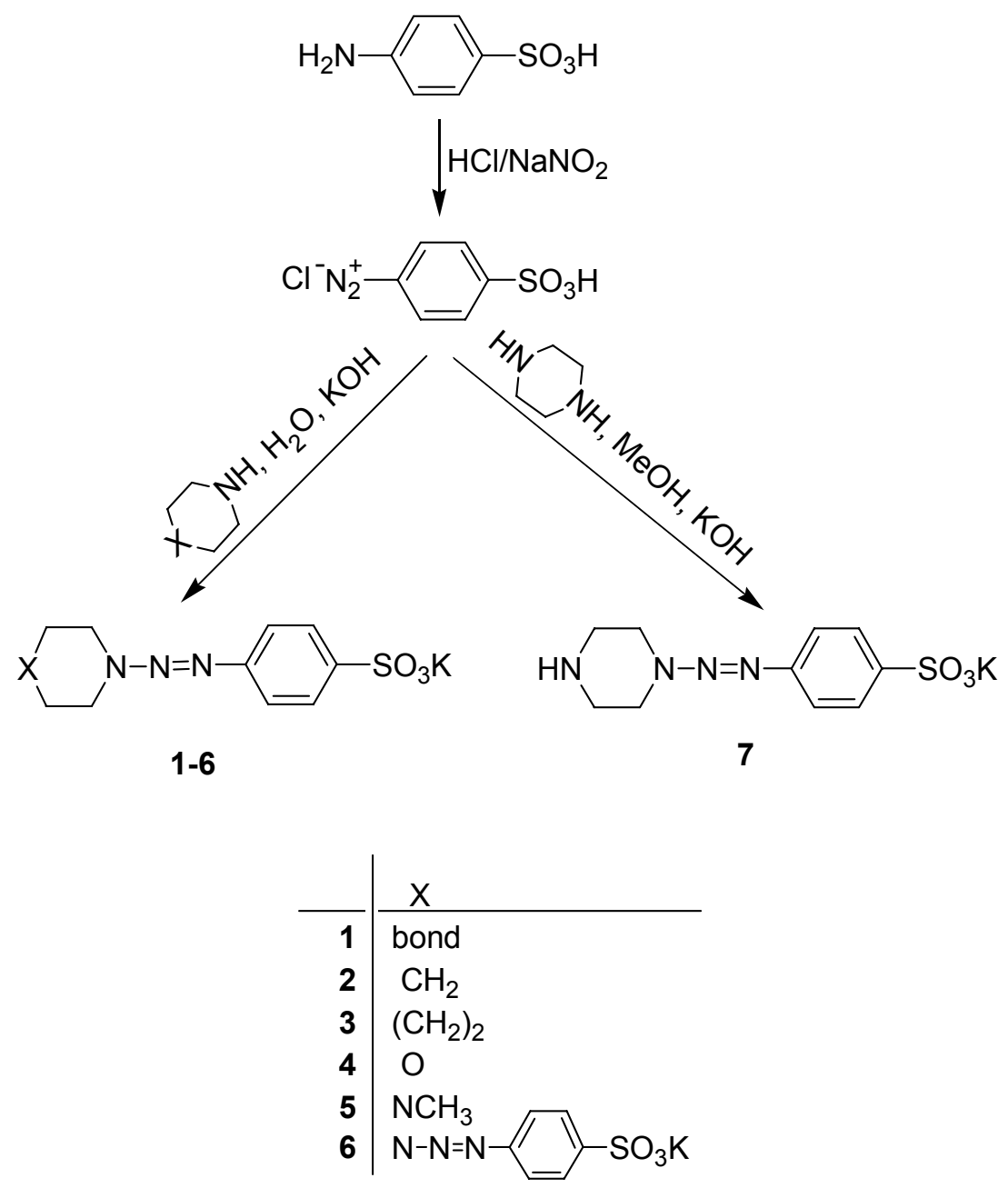

The structures of the synthesized compounds were confirmed by their ${ }^{1} \mathrm{H}-\mathrm{NMR}$, IR, and Raman spectra as well as satisfactory elemental analysis. It is important to note that the presence of the $>\mathrm{N}-$ $\mathrm{N}=\mathrm{N}$ - group was characterized by the very strong Raman band in the vicinity of $1420-1463 \mathrm{~cm}^{-1}$ related to the stretching vibration of $\mathrm{N}=\mathrm{N}$ bond $[12,13]$. Because of the high polarizability of the $>\mathrm{N}-$ $\mathrm{N}=\mathrm{N}$ fragment, Raman spectroscopy is particularly useful for the identification of the aminoazo function. The physical properties and spectral data of the synthesized compounds 1-7 are summarized in Table 1. 
Table 1. Physical and spectral properties of the potassium salts of N,N-disubstituted aminoazobenzenesulfonic acids 1-7.

\begin{tabular}{|c|c|c|c|c|}
\hline Compound & Yield, \% & M. p., ${ }^{\circ} \mathrm{C}$ & ${ }^{1} \mathrm{H}-\mathrm{NMR}, \delta$, ppm. & $\begin{array}{l}\text { Raman spectra, } \\
\Delta v(\mathbf{N}=\mathbf{N}), \mathbf{c m}^{-1}\end{array}$ \\
\hline 1 & 63 & $277-280$ & $\begin{array}{l}7.39 \text { and } 7.78\left(4 \mathrm{H} \text {, two d, } \mathrm{J}=9 \mathrm{~Hz}, \mathrm{C}_{6} \mathrm{H}_{4}\right), 3.60 \\
\left(4 \mathrm{H}, \text { br.s, } \mathrm{CH}_{2} \mathrm{NCH}_{2}\right), 1,96\left(4 \mathrm{H}, \mathrm{m},\left(\mathrm{CH}_{2}\right)_{2}\right)\end{array}$ & 1423 \\
\hline 2 & 65 & $260-263$ & $\begin{array}{l}7.42 \text { and } 7.81\left(4 \mathrm{H} \text {, two d, } \mathrm{J}=9 \mathrm{~Hz}, \mathrm{C}_{6} \mathrm{H}_{4}\right), 3.66 \\
\left(4 \mathrm{H} \text {, br s, } \mathrm{CH}_{2} \mathrm{NCH}_{2}\right), 1,58\left(6 \mathrm{H} \text {, br.s, }\left(\mathrm{CH}_{2}\right)_{3}\right)\end{array}$ & 1433 \\
\hline 3 & 60 & $267-270$ & $\begin{array}{l}7.42 \text { and } 7.77\left(4 \mathrm{H} \text {, two d, } \mathrm{J}=9 \mathrm{~Hz}, \mathrm{C}_{6} \mathrm{H}_{4}\right), 3.66 \\
\text { and } 3.91\left(4 \mathrm{H} \text {, two t, } \mathrm{CH}_{2} \mathrm{NCH}_{2}\right), 1.40-2.00 \\
\left(8 \mathrm{H}, \mathrm{m},\left(\mathrm{CH}_{2}\right)_{4}\right)\end{array}$ & 1420 \\
\hline 4 & 73 & $272-274$ & $\begin{array}{l}7.46 \text { and } 7.80\left(4 \mathrm{H}, \text { two dd, } \mathrm{J}=9 \mathrm{~Hz}, \mathrm{C}_{6} \mathrm{H}_{4}\right) \\
3.82\left(4 \mathrm{H}, \mathrm{s},\left(\mathrm{CH}_{2}\right) \mathrm{O}\left(\mathrm{CH}_{2}\right)\right)\end{array}$ & 1436 \\
\hline 5 & 58 & $264-267$ & $\begin{array}{l}7.47 \text { and } 7.79\left(4 \mathrm{H}, \text { two d, J=9 } \mathrm{Hz}, \mathrm{C}_{6} \mathrm{H}_{4}\right), 3.80 \\
\left(4 \mathrm{H}, \mathrm{t}, \mathrm{N}-\mathrm{N}\left(\mathrm{CH}_{2}\right)\right), 2.61\left(4 \mathrm{H}, \mathrm{t}, \mathrm{CH}_{2} \mathrm{NCH}_{2}\right) \\
2.30\left(3 \mathrm{H}, \mathrm{s}, \mathrm{CH}_{3}\right)\end{array}$ & 1435 \\
\hline 6 & 57 & $296-298$ & $\begin{array}{l}7.55 \text { and } 7.86\left(4 \mathrm{H}, \text { two d, } \mathrm{J}=9 \mathrm{~Hz}, \mathrm{C}_{6} \mathrm{H}_{4}\right), 4.08 \\
\left(8 \mathrm{H}, \mathrm{s}, \mathrm{CH}_{2}\right)\end{array}$ & 1463 \\
\hline 7 & 48 & $275-277$ & $\begin{array}{l}7.46 \text { and } 7.81\left(4 \mathrm{H} \text {, two d, J=9 Hz, } \mathrm{C}_{6} \mathrm{H}_{4}\right), 3.74 \\
\left(4 \mathrm{H}, \mathrm{t},=\mathrm{N}-\mathrm{N}\left(\mathrm{CH}_{2}\right)\right), 2.89\left(4 \mathrm{H}, \mathrm{t}, \mathrm{CH}_{2} \mathrm{NHCH}_{2}\right)\end{array}$ & $\begin{array}{c}1435 \\
\text { IR } v(\mathrm{~N}-\mathrm{H}), 3293 \mathrm{~cm}^{-1}\end{array}$ \\
\hline
\end{tabular}

Several of the synthesized compounds showed promising activity in preliminary tests of antiinflammatory action on carrageenin- and bentonite-induced oedema in rats according to reported protocols $[14,15]$.

\section{Conclusions}

A simple and convenient method was developed for the synthesis of several novel water-soluble potassium salts of 4-substituted aminoazobenzenesulfonic acids employing the reaction of insoluble 4-sulfobenzenediazonium chloride with cyclic and heterocyclic amines of various ring sizes. The compounds obtained have shown some potential activity in biological testing.

\section{Experimental}

\section{General}

All melting points are uncorrected. ${ }^{1} \mathrm{H}-\mathrm{NMR}$ spectra were recorded on a JEOL 90 instrument in $\mathrm{D}_{2} \mathrm{O}$, using 2,2-dimethyl-2-silapentane-5-sulfonic acid (DSS) as an internal standard. Infrared spectra 
were recorded for KBr disks on a Perkin-Elmer Spectrum GX FT-IR spectrometer, and Raman spectra of crystals were acquired on a Perkin-Elmer NIR Spectrum GX FT-Raman spectrometer. FT-Raman spectra were excited with the Nd-YAG laser operating at $1064 \mathrm{~nm}$ wavelength. All compounds gave satisfactory microanalysis ( $\pm 0.3 \%$ for $\mathrm{C}, \mathrm{H}, \mathrm{N}$ and $\mathrm{S}$, and $\pm 1.0 \%$ for $\mathrm{K}$ ).

General procedure for the preparation of the potassium salts of N,N-disubstituted 4-aminoazobenzenesulfonic acids (1-6). The appropriate amine $(0.05 \mathrm{~mol})$ was added at room temperature to a stirred suspension of 4-sulfobenzenediazonium chloride $(0.01 \mathrm{~mol})$ in water $(20 \mathrm{~mL})$ and stirring was continued for $10 \mathrm{~min}$. The reaction temperature was then gradually raised to $50{ }^{\circ} \mathrm{C}$, and after 10 minutes a clear faintly yellow solution was obtained. The solution was then treated with $\mathrm{KOH}(0.1$ mol) in methanol $(20 \mathrm{~mL})$ and this mixture was heated to reflux and then left to crystallize. Crystals were collected by filtration, washed with acetone and recrystallized from methanol-water (compounds 1-5) or water (compound 6).

Potassium salt of 4-(piperazin-1-ylazo)benzenesulfonic acid (7). Piperazine (0.05 mol) was dissolved in methanol $(40 \mathrm{~mL})$ and 4-sulfobenzenediazonium chloride $(0.01 \mathrm{~mol})$ was added. The reaction mixture was refluxed for $10 \mathrm{~min}$. The solution was then filtered and $\mathrm{KOH}(0.035 \mathrm{~mol})$ in water (10 $\mathrm{mL}$ ) was added to the filtrate. The resulting mixture was heated to reflux and then left to crystallize. The product was filtered off and recrystallized from 1:1 methanol-water to give the title compound as pale yellow crystals.

\section{References}

1. a) Lazny R.; Poplawski, J.; Kobberling J.; Enders D.; Brase S. Triazenes: a useful protecting strategy for sensitive secondary amines. Synlett, 1999, 1304-1306; (b) Wu Z.; More J.S. Iodinepromoted decomposition of 1-aryl-3,3-dialkyltriazenes: a mild method for the synthesis of aryl iodides. Tetrahedron Lett., 1994, 35, 5539-5542.

2. Kolar G. F. Synthesis of biologically active triazenes from isolable diazonium salts. Z. Naturforsch. 1972, 27, 1183-1185.

3. Das P. J.; Khound S. Synthesis of 1-aryl-3,3-disubstituted triazenes on ion-exchange resin support. Tetrahedron, 1994, 50, 9107-9113.

4. Sava G.; Giraldi T.; Lassiani L.; Nisi C. Antimetastatic acction and hematological toxicity of p(3,3-dimethyl-1-triazeno)benzoic acid potassium salt and 5-(3,3-dimethyl-1-triazeno)-imidazole-4carboxamide used as prophylactic adjuvants to surgical tumor removal in mice bearing B16 melanoma. Cancer Res., 1984, 44, 64-68.

5. Kažemėkaitė M.; Šimkevičienė V.; Talaikytė Z. Antileucemic activity of 4-(3,3-dimethyltriazeno)N-acylbenzenesulfonamides. Biologija (Vilnius), 2000, 242-244. 
6. Sava G.; Perissin L.; Lassiani L.; Zabucchi G. Antiinflammatory action of hydrosoluble dimethyltriazenes on the carrageenin-induced edema in Guinea pigs. Chem.-Biol. Interact., 1985, $53,37-43$.

7. Kažemėkaitė M.; Stumbrevičiūtė Z.; Astrauskas V. Aryltriazenes. 1. Synthesis and antiinflammatory activity of 4-(3,3-dimethyltriazene)-N-acylbenzenesulfamides (in Russian). Khim. Pharm Zh., 1997, 31, 37-39.

8. Giraldi T.; Sava G.; Cuman R.; Nisi C.; Lassiani L. Selectivity of the antimetastatic and cytotoxic effects of 1-p-(3,3-dimethyl-1-triazeno)benzoic acid potassium salt, $( \pm$ )-1,2-di(3,5-dioxopiperazin1-il)propane and cyclophosphamide in mice bearing Lewis lung carcinoma. Cancer Res., 1981, 41, 2524-2528.

9. Larsen J. S.; Zahran M. A.; Pedersen E. B.; Nielsen C. Synthesis of triazenopyrazole derivatives as potential inhibitors of HIV-1. Monatsh. Chem., 1999, 103, 1167-1173.

10. Sava G.; Geraldi T.; Lassiani L. Effects of isomeric aryldimethyltriazenes on Lewis lung carcinoma growth and metastases in mice. Chem.-Biol. Interact., 1983, 46, 131-136.

11. Tietze L.F.; Eicher T. Reaktionen und Synthesen im organisch-chemishen Praktikum und Forschungslaboratorium. G. Thieme, Stuttgart, New York, 1991.

12. Zimmermann F.; Lippert Th.; Beyer Ch.; Stebani J.; Nuyken O.; Wokaun A. N=N vibrational frequencies and fragmentation patterns of substituted 1-aryl-3,3-dialkyl-triazenes: comparison with other high-nitrogen compounds. Applied Spectrosc., 1993, 47, 986-993.

13. Scholz A.; Wokaun A. Assignment of $\mathrm{N}=\mathrm{N}$ vibrational frequencies and tautomeric effects in the vibrational spectra of 1-aryl-3-alkyl-3-hydroxy-triazenes and their platinum complexes. Applied Spectrosc., 1995, 49, 1834-1840.

14. Winter C.A.; Risley E.A.; Nuss G.W. Carrageenin-induced oedema in hind paw of rat as the assay for antiinflammatory drugs. Proc. Soc. Exp. Biol.(N.Y.)., 1962, 3, 544-547.

15. Marek J. Bentonite-induced rat paw oedema as a tool for simultaneous testing of prophylactic and therapeutic effects on anti-inflammatory and other drugs. Pharmazie, 1981, 36, 46-49.

Sample Availability: Available from the authors.

C 2002 by MDPI (http://www.mdpi.org). Reproduction is permitted for noncommercial purposes. 